\title{
Fresh State and Mechanical Properties of Self Compacting Concrete Incorporating High Volume Fly Ash
}

\author{
N. Mohamad ${ }^{1, a}$, M. S. Zulaika ${ }^{1}$, A. A. A. Samad ${ }^{1}$, W. I. Goh ${ }^{1}$, J. Hadipramana ${ }^{1}$ and A. Wirdawati ${ }^{1}$ \\ ${ }^{1}$ Jamilus Research Center, University Tun Hussein Onn Malaysia, 86400 Parit Raja, Johor, Malaysia
}

\begin{abstract}
Self-compacting concrete is considered as a concrete which can be placed and compacted under its own weight without vibration. The elimination of the need for compaction leads to better quality concrete and substantial improvement of working conditions. This paper investigates the fresh state and mechanical properties of self-compacting concrete incorporating high volume fly ash. Fly Ash (FA) was mixed into self-compacting concrete (SCC) as a replacement for cement. Portland cement (PC) was partially replaced with $0 \%, 20 \%, 40 \%$ and $60 \%$ FA. The water to binder ratio was fixed at 0.4 for all mixtures. Tests were carried out on all mixtures to obtain the workability of self-compacting concrete in terms of viscosity by slump flow test (Diameter and $\mathrm{T}_{500}$ ), $\mathrm{V}$-funnel and J-ring. The mechanical property tests were conducted on SCC cubes and cylinders to determine its compressive strength and modulus of elasticity. The results indicate that replacement of $40 \%$ fly ash is the optimum result for the workability and mechanical properties test. The highest compressive strength which is 27.2 MPa was achieved by SCC with $40 \%$ FA replacement. Modulus of elasticity increased with the increased percentage of fly ash except for $60 \%$ fly ash.
\end{abstract}

\section{Introduction}

Conventional concrete has been widely used in construction all over the world. It is the second consumed material after water in the world. The preparation of concrete includes batching, mixing, placing and compacting. It is essential to condense the concrete so that it should completely cover the reinforcement and fill all the space in the formwork to meet the strength and durability requirement. The air entrained in concrete during amalgamation has to be totally expelled out for getting uniform dense mass. If compaction is incomplete, it will lead to reduction in strength and performance of the concrete structure. The compaction becomes complex when percentage of reinforcement is high which does not allow insertion of vibrator at certain places. The vibration will also increase the noise level in and around the construction site [1].

Self-compacting concrete (SCC) is a highly flowable non-segregated concrete which spread into place and does not require vibration. SCC is the modified concrete with the use of chemical (superplasticizers and viscosity modifiers) and mineral (fly ash, slag, silica fume) admixtures in the concrete [2]. It is designed generally with high content of fine material. The three essential properties of self-compacting concrete are its ability to flow under its own mass (filling ability), its ability to pass

\footnotetext{
${ }^{a}$ Corresponding author : noridah@uthm.edu.my
} 
through congested reinforcement (passing ability), and its ability to resist segregation (segregation resistance).

Advantages of SCC include faster construction, reduction in man power, easier placing, uniform and complete consolidation, better surface finishes, improved durability, increased strength and safer working environment. Recently, many countries report the benefits of SCC by eliminating the need for vibration, shorter construction period, lower overall costs and also improved health and safety conditions [3].

This paper reports the fresh state and mechanical properties of SCC incorporating high volume of fly ash. The fresh state properties of SCC were determined by using mixture designed by Bouzoubaa and Lachemi [4]. The mechanical properties of SCC which include density, compressive strength, and modulus of elasticity were determined by conducting a compressive strength test on SCC cubes and cylincers. All tests were conducted according to British Standard code [5, 6, 7]. Substituting Portland cement with fly ash will make the concrete more workable and suitable for the construction. SCC concrete incorporating high volume of fly ash is able to produce concrete with compressive strength similar or higher than conventional concrete.

\section{Experimental Programme}

\subsection{Mixture design}

Generally, batching of materials by volume are often used in the design of concrete mixture due to the importance of the need to fill the voids between the aggregate particles [8]. The hardened properties of SCC are expected to be similar to those of vibrated normal concrete. Laboratory and field tests have demonstrated that the SCC hardened properties are indeed similar to those of vibrated concrete. Table 1 shows the mechanical properties of SCC as obtained from Hajime et al. [3].

\subsection{Materials and methods}

Self-compacting concrete specimen were formed by applying material such as cement, water, fine aggregate, coarse aggregates, fly ash and superplasticiser. Cube compression tests were conducted at 7, 28 and 56 days of curing ages. Table 2 shows the mixture proportion of the self-compacting concrete incorporating high volume of fly ash.

Table 1. Mechanical properties of SCC [3].

\begin{tabular}{lc}
\hline Water-binder ratio (\%) & 25 to 40 \\
Air content (\%) & $4.5-6.0$ \\
Compressive strength (28 days) (MPa) & 40 to 80 \\
Compressive strength (91 days) (MPa) & 55 to 100 \\
Splitting tensile strength (28 days) (MPa) & 2.4 to 4.8 \\
Elastic modulus (GPa) & 30 to 36 \\
Shrinkage strain $\left(\times 10^{-6}\right)$ & 600 to 800 \\
\hline
\end{tabular}


Table 2. Mix design for SCC.

\begin{tabular}{ccccccccc}
\hline Mix & $\begin{array}{c}\text { Cement } \\
\left(\mathbf{k g} / \mathbf{m}^{\mathbf{3}}\right)\end{array}$ & $\begin{array}{c}\text { Fly Ash } \\
\left(\mathbf{k g} / \mathbf{m}^{\mathbf{3}}\right)\end{array}$ & $\begin{array}{c}\text { Fly } \\
\mathbf{A s h} \\
\mathbf{( \% )}\end{array}$ & $\begin{array}{c}\text { Fine } \\
\text { Aggregates } \\
\left(\mathbf{k g} / \mathbf{m}^{\mathbf{3}}\right)\end{array}$ & $\begin{array}{c}\text { Coarse } \\
\text { Aggregates } \\
\left(\mathbf{k g} / \mathbf{m}^{\mathbf{3}}\right)\end{array}$ & $\begin{array}{c}\text { Water } \\
\left(\mathbf{l} / \mathbf{m}^{\mathbf{3}}\right)\end{array}$ & $\begin{array}{c}\text { SP } \\
\left(\mathbf{l} / \mathbf{m}^{\mathbf{3}}\right)\end{array}$ & $\begin{array}{c}\text { W/P } \\
\text { ratio }\end{array}$ \\
\hline TR1 & 450 & - & - & 851 & 851 & 180 & 9 & 0.4 \\
TR2 & 180 & 270 & 60 & 851 & 851 & 180 & 9 & 0.4 \\
TR3 & 270 & 180 & 40 & 851 & 851 & 180 & 9 & 0.4 \\
TR4 & 360 & 90 & 20 & 851 & 851 & 180 & 9 & 0.4 \\
\hline
\end{tabular}

\section{Results and Discussion}

\subsection{Workability}

Table 3 shows results for workability the fresh concrete as obtained from slump flow test (Slump flow diameter and $\mathrm{T}_{500}$ ), $\mathrm{V}$-funnel, $\mathrm{V}$-funnel at $\mathrm{T}_{5 \min }$ and $\mathrm{J}$-ring for various $\mathrm{SCC}$ compositions. The results from the workability tests were obtained as explained in the following sections.

Table 3. Experimental result for workability test.

\begin{tabular}{ccccccc}
\hline & & \multicolumn{5}{c}{ Workability Tests } \\
\cline { 3 - 6 } Mix & Fly ash (\%) & \multicolumn{2}{c}{ Slump flow, SF } & \multicolumn{2}{c}{ V-funnel } \\
\cline { 3 - 6 } & & Diameter,(mm) & $\mathbf{T}_{\mathbf{5 0 0}}(\mathbf{s})$ & $\mathbf{V}$-funnel (sec) & $\mathbf{T}_{\mathbf{5} \text { min }}$ (sec) & (mm) \\
\hline 1 & Control SCC & 400 & - & $\geq 12$ & - & - \\
2 & 60 & 635 & 6 & 10 & +3 & 3 \\
3 & 40 & 675 & 4 & 8 & +2 & 2 \\
4 & 20 & 625 & 7 & 9 & +3 & 2.5 \\
\hline
\end{tabular}

\subsection{Slump flow test}

Results showed that for the SCC control mixture, the slump flow spread diameter was $400 \mathrm{~mm}$ while for $\mathrm{T}_{500}$ it did not achieve $500 \mathrm{~mm}$ flow spread. With the presence of $20 \%$ fly ash the slump flow spread diameter and $\mathrm{T}_{500}$ showed increment up to $625 \mathrm{~mm}$ and $7 \mathrm{~s}$, respectively. The $40 \%$ fly ash mixture recorded optimum workability compared to $60 \%$ fly ash SCC mixture. However, the spreading range obtained was all within the acceptable range which is from $500 \mathrm{~mm}$ to $700 \mathrm{~mm}$ [2]. The result are shown in Figure 1 and Figure 2 below.

\subsection{V-funnel test}

The time measured using the $\mathrm{V}$-funnel was in the range of 8 to 12 second depending mainly on the SCC mixture used. The lowest V-funnel flow time of 8 second was recorded for the SCC with $40 \%$ fly ash while the mixture with $60 \%$ fly ash had the highest flow time of 10 second. The graphical result is shown in Figure 3. 


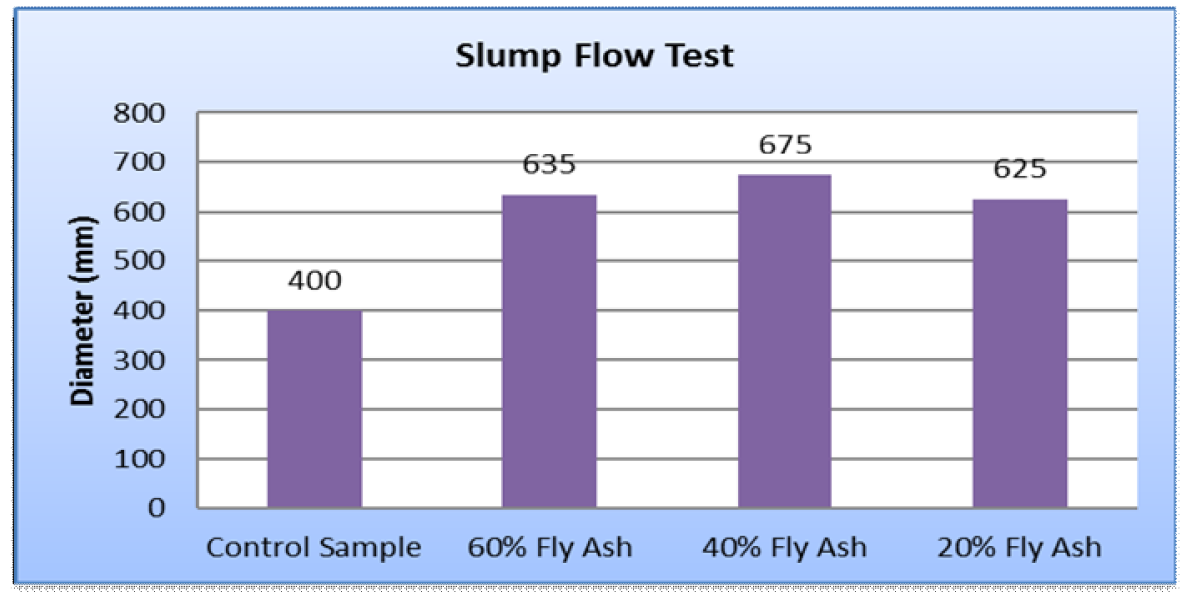

Figure 1. Slump flow test result.

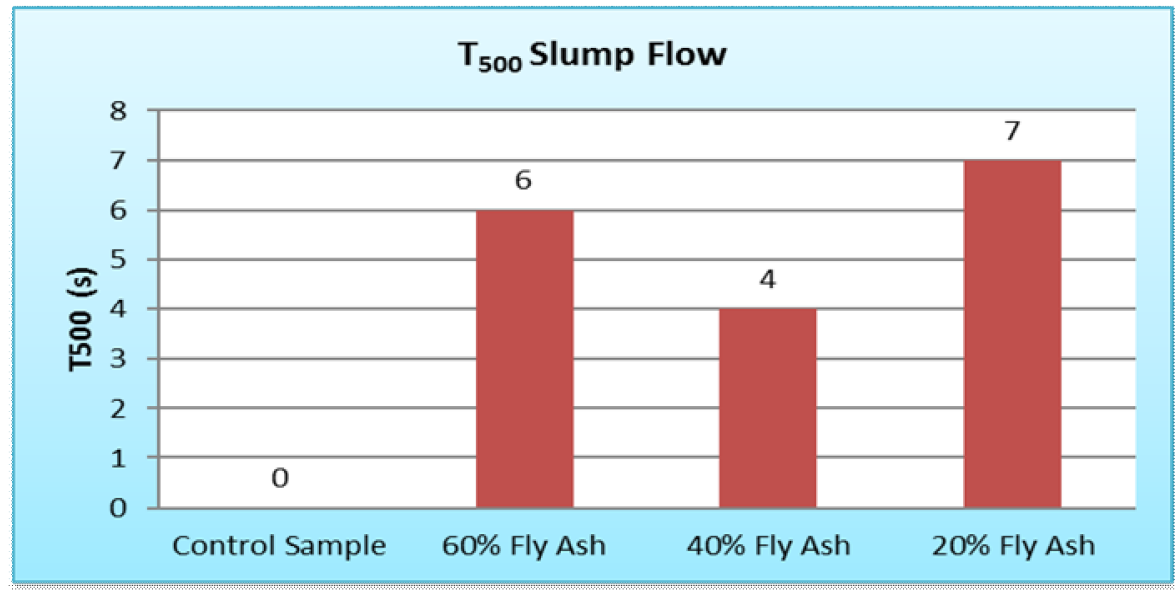

Figure 2. $\mathrm{T}_{500}$ slump flow.

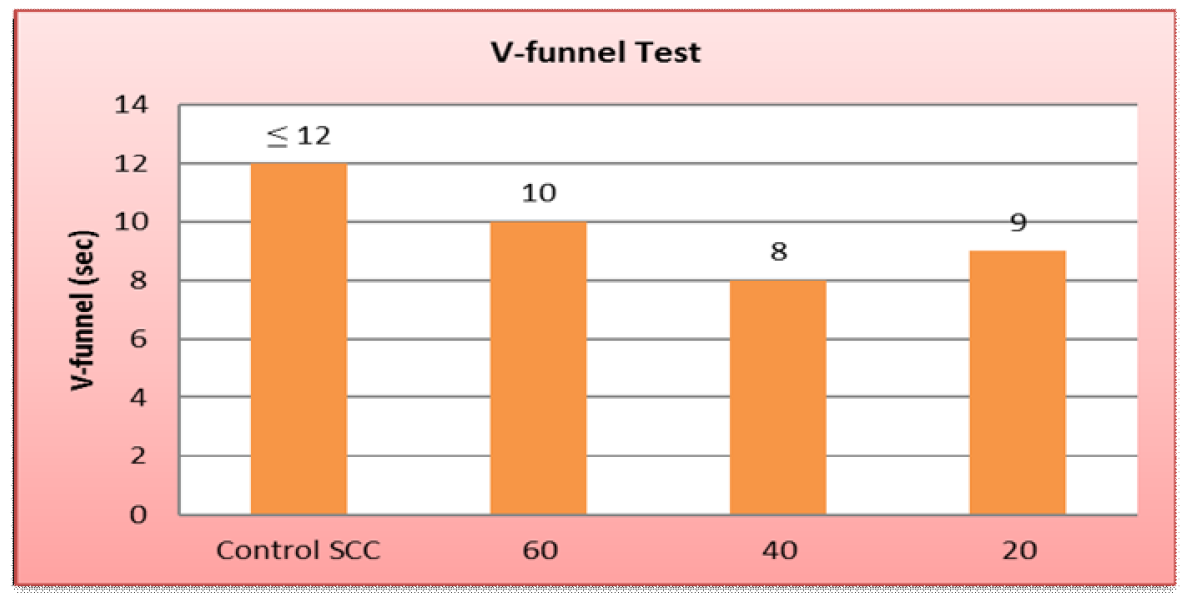

Figure 3. V-funnel result. 


\subsection{J-Ring test}

For J-Ring test, the test is to determine passing ability of the concrete. The blocking step, $\mathrm{B}_{\mathrm{j}}$, was determined by the average of the differences in height at four locations. Figure 4 shows the J-Ring result.

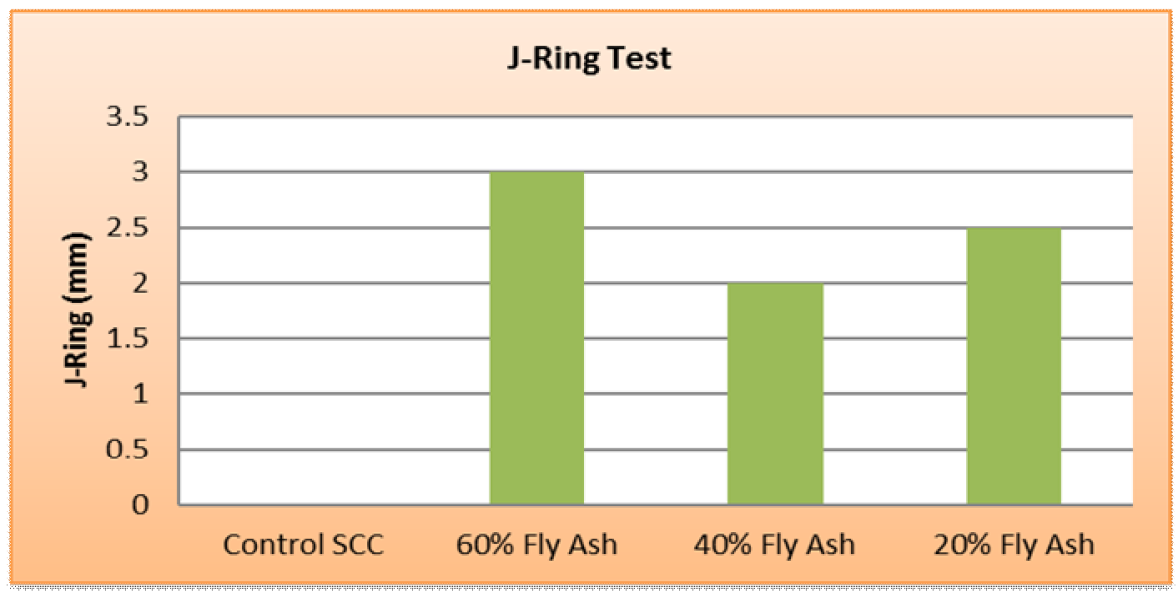

Figure 4. J-Ring results.

\section{Mechanical Properties}

\subsection{Compressive strength}

Figure 5 shows the average value of compressive strength for each type of concrete for the respective age of curing. The control SCC recorded compressive strength of 42.7, 46.1 and 50.5 MPa, at 7, 28, and 56 days of age, respectively. SCC contains $40 \%$ fly ash recorded the highest value of compressive strength which is $27.2,39.4$ and $43.9 \mathrm{MPa}$ at 7, 28 and 56 days, respectively. The lowest value of compressive strength goes to $60 \%$ fly ash which is $17.0,22.6$ and $28.5 \mathrm{MPa}$ at 7, 1428 and 56 days.

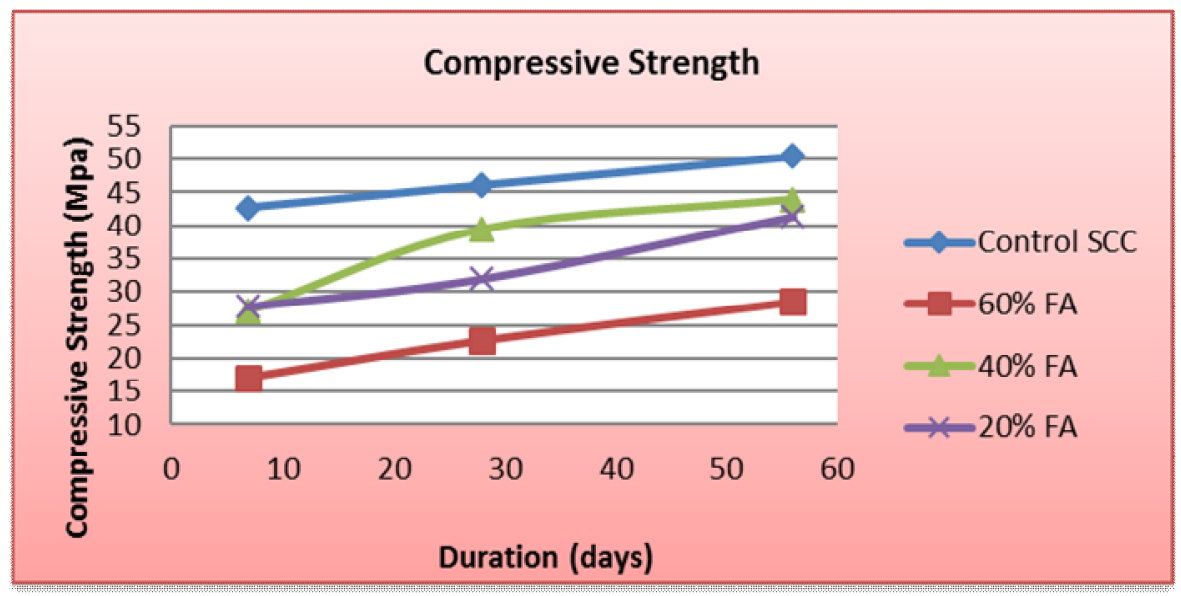

Figure 5. Results for compressive strength. 
Figure 6 shows that all of SCC mix design obtained the density within the same range which is $2200 \mathrm{~kg} / \mathrm{m}^{3}-2300 \mathrm{~kg} / \mathrm{m}^{3}$. This range of self-compacting concrete density obtained by all of the SCC mix design can be concluded to be in the same range as normal weight concrete which is from $2000 \mathrm{~kg} / \mathrm{m}^{3}$ to $2500 \mathrm{~kg} / \mathrm{m}^{3}$.

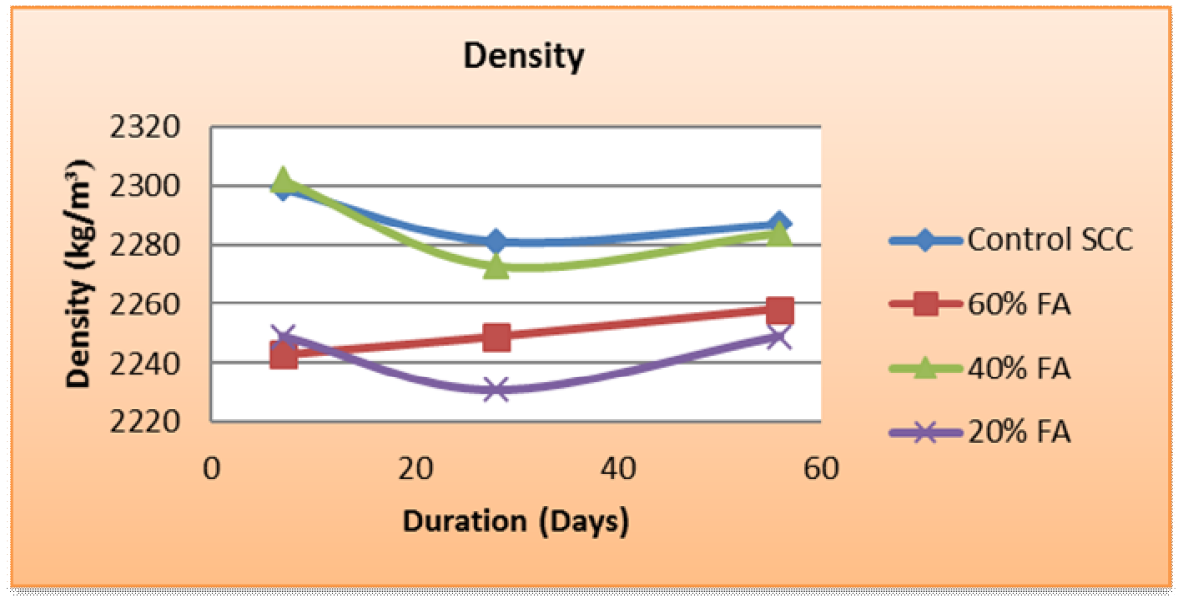

Figure 6. Results for concrete density.

\subsection{Modulus of Elasticity}

From the results shown in Figure 7, concrete cylinder containing 40\% fly ash show the highest value of modulus of elasticity (MOE) which is $31 \mathrm{GPa}$. In general, results of Modulus of Elasticity for Control SCC and other mixture showed the typical range for the static modulus of elasticity at 28 days based on British Standard, BS 8110 part 2, (1985).

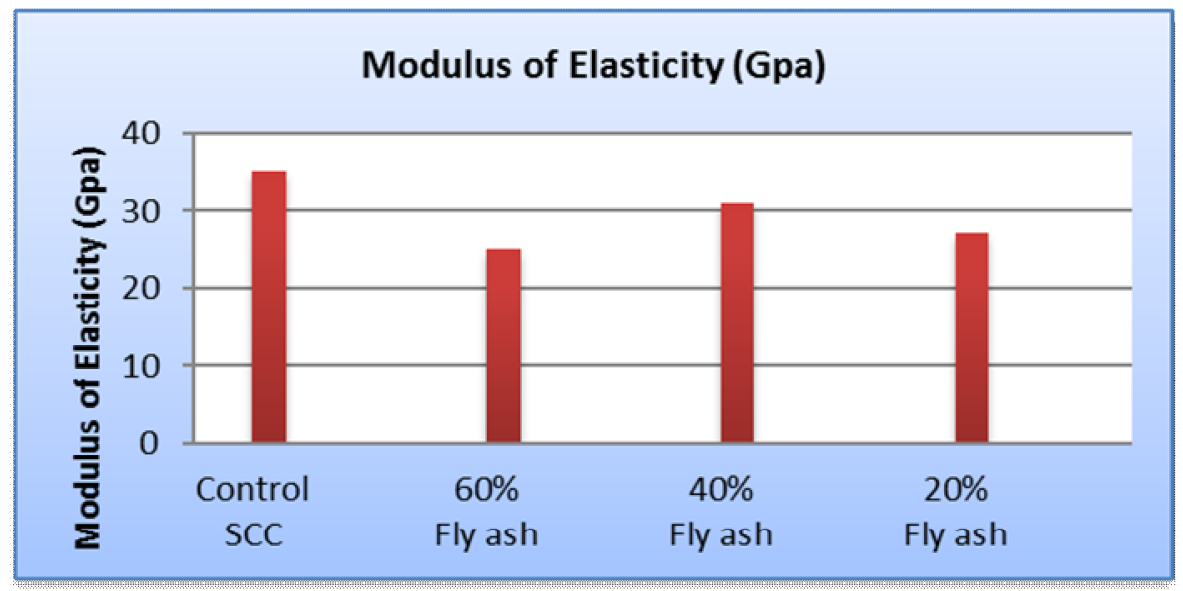

Figure 7. Results of modulus of elasticity. 


\section{Conclusions}

From the analyzed data, the main conclusions for the physical properties are:

i) The workability for fresh concrete increased as the percentage of fly ash increased except for the $60 \%$ fly ash. Overall result for Slump flow test (Diameter and $\mathrm{T}_{500 \mathrm{~mm}}$ ), V-funnel test and J-Ring test showed a stable mixture for concrete was produced from various mixture of SCC with different percentage of fly ash.

ii) A typical concrete mixture has the potential of producing lime. Fly ash chemically reacts with this lime to create more $\mathrm{CSH}$, the same "glue" produced by the hydration of cement and water. $60 \%$ of fly ash has higher potential to produce more CSH compared to $40 \%$ of fly ash. This is why the study showed optimum workability was obtained when SCC incorporated with $40 \%$ of fly ash.

iii) High percentage of Fly ash can be used to produce SCC with an adequate strength. Using up to $60 \%$ fly ash as Portland cement replacement can produce SCC with a strength as high as 30 $\mathrm{N} / \mathrm{mm}^{2}$.

Meanwhile, the main conclusions for the mechanical properties are:

i) The highest compressive strength was recorded by SCC mixture with $40 \%$ fly ash with 27.2 $\mathrm{MPa}, 39.4 \mathrm{MPa}$ and $43.9 \mathrm{MPa}$ at 7, 28 and 56 days, respectively. However, too much percentage of fly ash added will lead to deterioration of strength of the concrete. This is indicated from the results obtained from SCC mixture with $60 \%$ fly ash which recorded lowest compressive strength.

ii) The range of concrete density obtained is similar to the range of density in normal concrete which range from $2000 \mathrm{~kg} / \mathrm{m}^{3}$ to $2500 \mathrm{~kg} / \mathrm{m}^{3}$.

iii) Modulus of Elasticity (MOE) is shown to increase with the increase percentage of fly ash except for $60 \%$ fly ash. The result of MOE for the all the SCC mixtures are in the typical range for the static modulus of elasticity at 28 days based on British Standard, BS 8110 part 2, (1985).

\section{Acknowledgement}

The authors would like to thank Universiti Tun Hussein Onn Malaysia for its support in this research.

\section{References}

[1] K.S Sable and M.K. Rathi, Comparison of normal compacted concrete and self compacted concrete in shear and torsion, International Journal of Computer Technology and Electronics Engineering, 2(4), 74-79, (2012).

[2] N. Bouzoubaa and M. Lachemi, Self-compacting concrete incorporating high volumes of class F fly ash: Preliminary results, Cement and Concrete Research, 31(3), 413-420, (2001).

[3] H. Okamura and M. Ouchi, Self-compacting concrete, Journal of Advance Concrete Technology, Japan Concrete Institute, 1(1), 5-15, (2003).

[4] British Standard, Testing Concrete-Part 114: Determination of Density of Hardened Concrete, BS1881-114, (1983).

[5] British Standard, Testing Concrete-Part 116: Method for Determination of Compressive Strength of Concrete Cubes, BS 1881-116, (1983)

[6] British Standard, Testing Concrete-Part 121: Method for Determination of Static Modulus of Elasticity in Compression, BS 1881-121, (1983).

[7] Z. Grdić, I. Despotović and G. Topličić-Ćurčić, Properties of self-compacting concrete with different types of additives, Facta Universitatis - Series: Architecture an Civil Engineering, 6(2), 173-177, (2008). 